Recebido: 01/12/2014

Aprovado: 28/05/2015

\title{
Entre a Monarquia e a República: imagens de Tiradentes em Joaquim Norberto de Souza e Silva e Lúcio José dos Santos
}

\author{
Giuslane Francisca da Silva* \\ Luciana Coelho Gama**
}

Resumo: A construção discursiva do indivíduo histórico Tiradentes deu-se em ambiente de embate político, em que autores monarquistas e republicanos estabeleceram suas falas de acordo com a conjuntura de poder na qual estavam inseridos. Nesse sentido, buscamos analisar os discursos acerca de Tiradentes, na visão do monarquista Joaquim Norberto de Souza e Silva e do republicano Lúcio José dos Santos, intelectuais cujas obras são representativas dos discursos divergentes em questão, sendo pontos de referência para trabalhos sobre Tiradentes e a Inconfidência até os dias atuais.

Palavras- chave: Tiradentes; Discurso; Poder

Abstract: The discursive construction of the historical individual Tiradentes occurred in an atmosphere of political clashes, when monarchists and republicans' authors established their lines according to the situation of power in which they were placed. In this way, the study aims to analyze the discourses about Tiradentes, from the monarchist view of Joaquim Norberto de Souza e Silva and republican view of Lúcio José dos Santos. These intellectuals have important works that represent the divergent discourses in point, which are reference to work about Tiradentes and the Conspiracy to the present day.

Keywords: Tiradentes; Discurse; Power

\footnotetext{
* Mestranda em História pela Universidade Federal de Mato Grosso. Bolsista CAPES.

** Mestranda em História pela Universidade Federal de Mato Grosso.
} 


\section{Introdução}

A construção da identidade de um povo em torno da ideia de nação é um processo complexo, que passa pela elaboração de símbolos legitimadores do poder constituído. Tais simbologias devem ser aceitas pela população, que as incorpora como representações naturais do sentimento patriótico. O herói nacional é um desses símbolos, devendo ser uma figura que integra os diferentes grupos sociais em torno do ideário nacionalista. Segundo Paulo Miceli:

O resultado é que soldados, empresários, jogadores de futebol, empresários todos, enfim - antes de pertencerem a classes sociais, grupos e subgrupos de interesses ou categorias profissionais ou religiosas, antes de sua própria individualidade, parecem identificados por um fim único e permanente: a nação, umas das formas mais sutis e dominadoras de sabedoria social e uma das principais instituições criadas para estabelecer e manter os mecanismos de dominação política (MICELI, 1994: 14).

Nesse sentido, o objetivo desse artigo, é discutir os discursos a respeito de Tiradentes, na perspectiva de um intelectual monarquista, Joaquim Norberto de Souza e Silva, e de um republicano, Lúcio José dos Santos, analisando como cada um a partir de um momento histórico e do contexto político no qual estavam inseridos, procurou construir a figura de Tiradentes.

No que diz respeito à formação do sentimento nacionalista brasileiro, temos na figura de Joaquim José da Silva Xavier, militar que viveu na capitania de Minas Gerais em finais do século XVIII, a expressão do ideal de herói nacional. Tiradentes, como ficou popularmente conhecido por exercer também o ofício de dentista, participou do movimento de cunho separatista "Inconfidência Mineira", sendo preso e condenado à morte pelo governo português. Sua posição social, tida como mais humilde em relação aos demais participantes do levante, bem como seu comportamento resignado diante do cadafalso em que foi enforcado sustentaram posições discursivas que o alçaram à categoria de herói e patrono cívico da nação brasileira. Segundo Carvalho (1990), Tiradentes reunia características que causavam empatia em grande parte da nação brasileira, como a religiosidade, o pacifismo e mesmo o fato de ter atuado em Minas Gerais, região de grande importância política.

Com o advento do movimento republicano no Brasil e a necessidade de construção de um herói que atendesse às expectativas da população, bem como aos interesses republicanos, a figura de Tiradentes surgiu como ideal, visto que a Inconfidência Mineira era associada à ideia de combate ao jugo português e realização da República (mesmo que, em finais do

\section{Alistotorias}


século XVIII, o mais provável era que os inconfidentes almejassem um sistema republicano apenas em Minas Gerais e áreas próximas, e não em nível do Brasil). Carvalho aponta outros "candidatos" ao posto de herói, tais como: Frei Caneca e os marechais Deodoro da Fonseca e Floriano Peixoto, entretanto o alferes mineiro representava melhor as aspirações republicanas e tinha maior aceitação junto ao povo:

Na figura de Tiradentes todos podiam identificar-se, ele operava a unidade mística dos cidadãos, os sentimentos de participação, de união em torno de um ideal, fosse ele a liberdade, a independência ou a república. Era o totem cívico. Não antagonizava ninguém, não dividia as pessoas e as classes sociais, não dividia o país, não separava o presente do passado nem do futuro (CARVALHO, 1990: 68).

Consideramos assim que o discurso republicano esforçou-se por construir a imagem de Tiradentes como herói nacional. Várias representações míticas foram criadas em torno do alferes, que passou a ser associado aos ideais cristãos e representado como o próprio Cristo. $\mathrm{O}$ pintor Décio Villares o retratou, em 1890, com barba e cabelos compridos, olhar sereno. Pedro Américo, em sua famosa pintura Tiradentes esquartejado (1893) reproduz o alferes mineiro já morto, também com cabelo e barba compridos, o corpo esquartejado e disposto num formato semelhante ao mapa do Brasil, tendo ao lado da cabeça e em posição de destaque o cristo crucificado.

Somando-se às imagens, Tiradentes era forjado como herói em escritos variados, como artigos jornalísticos e poemas. Contudo, além dos "candidatos" ao posto de herói nacional já citados acima, que correspondiam em maior ou menor grau aos interesses do poder republicano, havia forte embate político em torno do assunto. Grupos monarquistas consideravam o imperador Dom Pedro I, proclamador da Independência do Brasil, o nome mais apropriado para tal posição. Sobre o tema, Carvalho destaca a construção, em 1862, de uma estátua em homenagem a Dom Pedro I no largo do Rocio, local do Rio de Janeiro onde se acreditava que Tiradentes havia sido enforcado. Tal monumento gerou indignação e protestos republicanos, principalmente sendo o homenageado neto de d. Maria I, rainha de Portugal na ocasião do sacrifício do alferes.

$\mathrm{O}$ artigo do escritor abolicionista e republicano Luís Gama, intitulado "À forca o Cristo da multidão", de 1882, retrata bem a indignação de seu grupo político, que critica a homenagem a Dom Pedro I, ao mesmo tempo em que exalta Tiradentes. O autor, junto a outras vozes republicanas, bradava contra o monumento, considerado uma afronta à honrosa memória do inconfidente mineiro: 
Luís Gama leva ainda mais longe o paralelo entre Tiradentes e Cristo. A forca é equiparada à cruz, o Rio de Janeiro a Jerusalém, o Calvário ao Rocio. À transformação da forca em altar, acrescenta a transmutação do monumento a Pedro I em patíbulo imperial. Em vez da forca, tornada altar da pátria, construíram um monumento. Em vez da tragédia do martírio, exibiram a comédia da estátua (CARVALHO, 1990: 62).

Percebemos dessa forma que houve uma construção discursiva baseada nos preceitos republicanos, objetivando a estruturação de Tiradentes enquanto mártir nacional. Tal discussão surgiu como "resposta" aos discursos monarquistas, que pretendiam heroicizar Dom Pedro I e tendiam a desqualificar Tiradentes devido ao ideal republicano contido na Inconfidência Mineira. Tais influências do poder político já podiam ser verificadas nos primeiros estudos analítico-descritivos sobre Tiradentes e o levante mineiro, anos antes da Proclamação da República, e também após a mesma, conforme veremos a seguir.

Duas obras são emblemáticas no que diz respeito ao embate político e discursivo em torno do sujeito histórico Tiradentes: História da Conjuração Mineira (1873) do monarquista Joaquim Norberto de Souza e Silva e A Inconfidência Mineira - papel de Tiradentes na Inconfidência Mineira (1927), do republicano Lúcio José dos Santos. Ambos os estudos apresentam discursos contrastantes sobre o inconfidente, sendo o primeiro ícone e principal referência para as pesquisas sobre o tema durante o final do século XIX e princípio do século XX.

A descrição de Norberto, que será mais bem detalhada adiante, era de um Tiradentes medíocre e quase insignificante em comparação aos outros participantes da Inconfidência, pessoas cultas e de boa estirpe. Já Santos, buscando desconstruir o discurso monarquista e criar nova referência, em 1922 escreve A Inconfidência Mineira - papel de Tiradentes na Inconfidência Mineira, fazendo uma contraposição ao discurso de Norberto. $\mathrm{O}$ autor, alinhado aos interesses do poder republicano, traz a imagem de um Tiradentes forte e heroico, líder visionário convicto de seus ideais e que se sacrificou por eles, tendo seu sangue cristão derramado para defender a liberdade. Dito isso, analisaremos os escritos dos autores.

\section{Joaquim Norberto de Souza e Silva}

Joaquim Norberto de Souza e Silva (1820-1891) destacou-se como homem letrado em sua época, publicando poemas em jornais da corte, prosas de ficção, peças dramáticas e estudos históricos, além de ser um dos pioneiros na organização de obras poéticas para

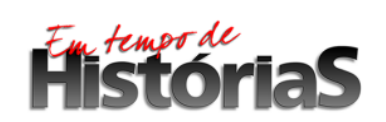


publicação em livros (SOUZA, 2009). Nascido no Rio de Janeiro, preocupou-se com aspectos sociais e políticos de seu tempo, como a frágil unidade nacional do Brasil, temendo que o país fosse dividido em pequenas repúblicas devido às revoltas do período regencial. Dessa forma, pode ser descrito como um intelectual nacionalista e atuante em relação às questões políticas do Império, defendendo um estado forte. Por se destacar em seus escritos, o autor foi indicado em 1841, ainda aos vinte e um anos de idade, para compor o quadro de membros do Instituto Histórico e Geográfico Brasileiro (IHGB) (SOARES, 2002), instituição criada com o objetivo de escrever a História do Brasil a partir de uma identidade própria, forte e centralizadora.

O IHGB teve como principal incentivador o Imperador Dom Pedro II, tendo compromisso com a legitimação do Estado monárquico. O imperador foi nomeado formalmente "protetor" da instituição em 1851 (GUIMARÃES, 1988). É justamente a partir daí que "Joaquim Norberto torna-se cada vez mais atuante no IHGB, voltando seus olhos também para os cargos da mesa diretora do Instituto onde um grupo seleto de homens de 'boa sociedade' gravitava em torno do Instituto e, portanto, do Imperador" (SOARES, 2002: 60).

Na década de 1860, Joaquim Norberto inicia as pesquisas de sua grande obra, História da Conjuração Mineira. Nesse estudo o historiador analisará, a partir dos Autos da Devassa da Inconfidência e duma Memória de autor anônimo, o movimento conspiratório mineiro contra o governo colonial. Apesar de estar fortemente ligado à monarquia por ser membro do IHGB, o autor considerará sua descrição e análise dos fatos isenta de qualquer tipo de influência e, portanto, "neutra", pretensão recorrente entre os historiadores de seu tempo.

$\mathrm{O}$ autor trabalha por dez anos nas pesquisas sobre o tema, até que, com o advento do movimento republicano em 1870, apressa a publicação de seus escritos. Joaquim Norberto preocupa-se com a apropriação da imagem de Tiradentes pelos republicanos, já evidente em 1872, "quando foi proposta a construção de um monumento a Tiradentes no Rio de Janeiro. Norberto declarou-se contrário à ideia, por considerar a figura de Tiradentes secundária" (CARVALHO, 1990: 62). O monarquista publica então sua obra o mais rápido possível, já no ano seguinte. $\mathrm{O}$ autor era declaradamente contra a heroicização do inconfidente e procura com seu estudo desmistificar a construção da imagem idealizada de mártir cristão e patriótico, que já vinha sendo atribuída ao alferes. Norberto chega mesmo a denegrir a figura de Tiradentes, inclusive no que diz respeito a seus aspectos físicos e psicológicos. Segundo o autor:

Era ele de estatura alta, de espáduas bem desenvolvidas, como os naturais da capitania de Minas Gerais. A sua fisionomia nada tinha simpática e antes se tornava notável pelo que fosse de repelente, devido em grande parte ao seu 
olhar espantado. Possuía, porém, o dom da palavra e expressava-se as mais das vezes com entusiasmo; mas sem elegância nem atrativo, resultado de sua educação pouco esmerada; ouvindo-o porém na rudeza de sua conversação, gostava-se da sua franqueza selvagem, algumas vezes por demais brusca e que quase sempre degenerava em leviandade, de sorte que uns lhe davam o característico de herói e outros o de doido. Tornava-se assim o objeto de público gracejo, provocando o riso, e não poucas vezes as vaias e apupadas do vulgo (SILVA, 1948: 28).

A descrição apresentada procura construir um homem de aspecto desprezível e aparência física desagradável. O dom da palavra é reconhecido pelo autor como uma das qualidades do alferes, porém este não soube aproveitá-lo da melhor forma, agindo por vezes de forma leviana e pouco elegante em seus discursos. Estas características provavelmente impediram Tiradentes de obter êxito em seus empreendimentos, fracassando como mascate e minerador e, sendo um militar de pouca expressão, não atingiu as glórias almejadas por sua ambição. Na interpretação do autor:

Vieram depois os anos e com os anos as decepções, e com elas o desânimo, e
em seguida o arrependimento e por fim o desejo de arrepiar caminho.
Lembrado sempre para as mais arriscadas diligências pela sua bravura, que
tinha o quer que fosse de fanfarronice; exato por jactância no cumprimento
de seus deveres, era contudo esquecido em todas as promoções que se
faziam em seu regimento. Condenado a ficar estacionário no posto de
alferes, atingira a idade de trinta e nove anos preterido pelos seus inferiores,
que lhe tomavam a dianteira e subiam em postos, tornando-se-lhe superiores.
Doía-se da injustiça, queixava-se com o azedume do ressentimento, e assim
ia ganhando a desafeição de seus camaradas (SILVA, 1948: 27).

Nota-se que o discurso de Joaquim Norberto retrata Tiradentes como um homem fracassado profissionalmente, e de personalidade pretenciosa, porém frustrada e ressentida. Para o autor, Tiradentes não era um homem mau, porém sua bondade pouco lhe serviu, não tinha estudo suficiente e não soube controlar os impulsos negativos de seu ego presunçoso e vaidoso. Era um homem intenso e apaixonado, foi forte defensor dos ideais de liberdade ao participar da Inconfidência, principalmente por sentir-se decepcionado com seus insucessos profissionais e empolgar-se com as notícias das revoluções europeias trazidas pelo doutor Álvares Maciel (idem: 29). Por sua loquacidade, Tiradentes tornou-se divulgador do levante mineiro, porém "com as suas leviandades mais deitava a perder a causa do que servia ao partido a que se ligara" (idem: 49).

Conforme verificado nessa breve análise, certamente o discurso de Joaquim Norberto não estava isento das influências do poder político ao qual estava ligado. Suas pesquisas estavam permeadas pelo posicionamento ideológico monarquista. De acordo com José Murilo

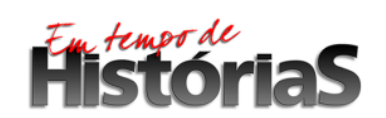

(PPGHIS/UnB) No. 26, Brasília, Jan- Jul 2015 ISSN 2316-1191 
de Carvalho, a obra do monarquista tornou-se "ponto de referência obrigatório nos estudos da Inconfidência que vieram posteriormente" (1990: 62). De fato, tratava-se do estudo mais completo já realizado sobre o tema até o momento, revelando episódios documentados, retirados dos Autos da Devassa. Ainda segundo Carvalho, Norberto respondeu às críticas que o acusavam de produzir um discurso tendencioso utilizando justamente esta documentação como justificativa. Alegava que sua pesquisa foi baseada em documentos verdadeiros, e que, portanto, trazia em sua obra informações verídicas e livres de deturpações influenciadas por suas convicções pessoais.

\section{Lúcio José dos Santos}

Considerando-se também livre de influências e capaz de produzir um discurso neutro, encontramos, já após a República estabelecida, o educador, engenheiro, jurista e historiador mineiro Lúcio José dos Santos (1875-1944). Foi professor da Escola de Engenharia de Belo Horizonte e em 1924 foi nomeado Diretor de Instrução Pública do Estado de Minas Gerais, cargo hoje equivalente ao de Secretário Estadual de Educação (OLIVEIRA, 1975). Em 1931, foi designado reitor da UMG (Universidade de Minas Gerais), cargo que ocupou por dois anos.

O intelectual destacava-se no campo social e político de Minas Gerais, tendo sido ainda nos primórdios da República (1896) eleito vereador pela Câmara Municipal de Ouro Preto $^{1}$. Dentro deste contexto, escreverá em 1922 A Inconfidência Mineira - papel de Tiradentes na Inconfidência Mineira. Nessa obra, o autor contestará o discurso monarquista do historiador Joaquim Norberto de Souza e Silva, criando com base nos argumentos republicanos, a imagem de um Tiradentes mártir e heroico.

Embora tenha sido publicado em 1927, o estudo de Santos foi elaborado por ocasião do centenário da Independência do Brasil, em 1922. O momento era bastante oportuno para uma obra em que Tiradentes aparece como herói da libertação nacional. A comissão organizadora do Congresso Internacional de História da América, em conferência realizada no Instituto Histórico e Geográfico Brasileiro, encomendou a obra em que o autor deveria tratar do levante de Minas Gerais como parte das comemorações de centenário da Independência do

\footnotetext{
${ }^{1}$ Informação obtida na galeria de biografias dos reitores da Universidade Federal de Minas Gerais (UFMG). Disponível em https://www.ufmg.br/80anos/reitores.html. Acesso em 05/07/2014.
} 
Brasil $^{2}$. Percebemos assim que o IHGB adaptou-se à República, ordem política vigente desde 1889, deixando de ser uma instituição com fortes inclinações monarquistas.

Lúcio dos Santos afirma que inicialmente pretendia escrever uma história geral da Inconfidência Mineira, porém ao deparar-se com o grande número de relatos sobre o assunto, sentiu-se compelido a escrever sobre o papel de Tiradentes no levante, procurando expor o que chama de verdades históricas. Segundo o autor:

Deste estudo paciente e desprevenido me veio a certeza de que muitos enganos correm por aí, a respeito da Inconfidência, amparados pelos melhores escritores que do assunto têm tratado. Muitos destes enganos provêm de leitura imperfeita do processo, da ignorância de determinadas circunstâncias, de interpretações tendenciosas ou mesmo de falta de senso crítico (SANTOS, 1927: Prefácio).

Nota-se já nesta fala a aspiração de Santos em desconstruir os discursos monarquistas sobre Tiradentes, pois os estudos anteriores ao seu trabalho teriam feito considerações erradas sobre o movimento separatista mineiro e seu participante mais famoso. O intelectual atribui esses erros à ignorância dos fatos ou mesmo às preferências pessoais dos autores, que não saberiam examinar os documentos com a devida isenção. Observamos no discurso de Lúcio dos Santos que ele, assim como seu antecessor Joaquim Norberto, pretendia transformar sua versão sobre o levante em verdade histórica. Há, no entanto, substanciais contradições entre os Tiradentes criados pelas narrativas dos dois autores.

Em sua obra, Lúcio José dos Santos constrói Tiradentes como uma figura agradável e simpática, numa visível oposição ao discurso de Joaquim Norberto. Segundo o autor, a imagem de um Tiradentes "feio e espantado" surgiu devido a uma declaração de Alvarenga Peixoto nos Autos da Devassa, e que posteriormente foi apropriada por Souza Silva para denegrir o alferes (idem: 125). Santos salienta ainda as várias áreas de trabalho em que Tiradentes atuou, afirmando que os fracassos obtidos não se deram por incompetência, mas antes por má sorte. Um exemplo seria a falta de recursos financeiros e de escravos, que impediam Tiradentes de prosperar na mineração. O historiador dá destaque também ao projeto de captação de águas para abastecimento do Rio de Janeiro, que foi rejeitado e considerado insano pelo Vice-Rei Luís de Vasconcelos, mas foi realizado de fato anos depois, afirmando assim que Tiradentes não foi um insano, mas antes um visionário incompreendido (idem: 133).

\footnotetext{
${ }^{2}$ Segundo prefácio de Francisco Iglêsias, na edição de 1972 de A Inconfidência Mineira, publicada pela imprensa Oficial, Belo Horizonte.
} 
Santos defende o pioneirismo de Tiradentes também em relação ao seu papel no levante mineiro. Para o autor, o alferes fazia parte do núcleo em que surgiu a ideia de conspiração contra o governo português, sendo o primeiro a articular a revolta. Além de lançar a ideia, Tiradentes teria abraçado a liderança da causa. Diz-nos o autor:

Feita esta primeira constatação, firmamos uma verdade, isto é, que no grupo mais decidido, núcleo da conjuração constituído por Tiradentes, Francisco de Paula, Maciel, Alvarenga, Padre Carlos, Padre Rollin, Francisco Antonio, Luiz Vaz e Domingos de Abreu, especialmente pelos seis primeiros, a prioridade da ideia coube a Tiradentes. Sem o prestígio que a alguns dos conjurados emprestava a glória literária, a outros a riqueza, a outros a posição social, Tiradentes ergue-se no meio de todos como chefe incontestável, não somente por ser o iniciador audaz, mas também pelo devotamento com que se entregou a essa nobre causa, devotamento tão grande que se tem podido parecer a muitos como atingindo as raias da loucura. [...] Condenado, foi ele pelos próprios juízes consagrado chefe da conjuração, como o paladino audaz e perigoso, cuja pena não pode ser de forma alguma atenuada. Executado, portou-se ele com serenidade, com uma coragem, com um desprezo da vida, muito raramente observados na História da humanidade (idem: 563-564).

A análise desse trecho, em que Lúcio José dos Santos examina sob sua ótica o papel de Tiradentes na Inconfidência, demonstra-nos claramente o posicionamento do autor, alinhado ao discurso do poder republicano. Tiradentes não foi apenas um participante da conspiração mineira, ele foi seu idealista e líder. O governo português condenou-o à morte justamente por ser o comandante e porta-voz do movimento, por isso era fundamental que sua execução servisse de exemplo contra novas revoltas, amedrontando a população.

As características antes destacadas como negativas por Joaquim Norberto, aqui, são revistas e contestadas. O inconfidente não era louco nem leviano, os que assim o interpretaram fizeram-no por não compreender seu espírito empreendedor, libertário e visionário, sendo tendenciosos. "Bazófia, prova de fraqueza de juízo: afirma J. Norberto. Como é possível julgar assim, sem estar possuído da mais radicada e invencível parcialidade?" (idem: 567). O alferes defendia seus anseios com fervor, era ousado e convicto de suas causas. Se muito falava, era pelo desejo de propagandear e difundir o movimento, ansioso por obter êxito em seu sonho libertador.

Percebemos a intenção de Santos em desconstruir o discurso de Norberto. Ele constata e critica em vários momentos a influência monarquista sobre a obra do autor. Porém, o próprio Santos não admite sofrer influências políticas e classifica sua obra como justa. Considera ter mantido a distância necessária para analisar os fatos imparcialmente, não sendo 
influenciado por ideais republicanos, e menos ainda monarquistas. "Pela minha parte, igualmente distante de tais extremos, pude evitar estas injustiças opostas" (idem: 30). Entretanto, evidentemente a construção discursiva do autor cria um Tiradentes nobre, inteligente, visionário, realista, de espírito elevado, enfim, um inquestionável herói martirizado. Ainda que se considere imparcial em comparação a Joaquim Norberto, o discurso de Santos está em sintonia com os interesses republicanos, que a esta altura já alçavam Tiradentes ao posto de herói da nação brasileira.

Concluímos que a obra de Lúcio José dos Santos trata-se de uma "resposta" à obra de Joaquim Norberto de Souza e Silva. Santos preocupa-se em opor seu discurso ao de Silva, principalmente no que diz respeito a Tiradentes. Sua obra é fruto do contexto social e político em que estava inserida, bem como dos ideais em que acreditava. Além disso, reforçamos que A Inconfidência Mineira trata-se de trabalho realizado sob encomenda para as comemorações do centenário da Independência do Brasil, num momento de consolidação do civismo e do projeto republicano no país.

\section{Discursos, o poder e a construção do herói}

Sabemos que nenhum trabalho historiográfico é capaz de traduzir a realidade. O que temos são representações do real, traduzidas em forma de texto escrito, como no caso das duas obras analisadas neste artigo. Sendo assim, é plausível que discursos e narrativas históricas sejam contestados, uma vez que não se configuram em verdades absolutas, e sim em versões da realidade apresentadas sob a ótica de seus autores, e interpretadas de diferentes formas sob o ponto de vista de quem lê. O próprio conceito de "verdade" é relativo e muda de acordo com o contexto e a época, conforme nos demonstra Michel Foucault:

Porque nos poetas gregos do século VI, o discurso verdadeiro - no sentido forte e valorizado do termo -, o discurso verdadeiro pelo qual se tinha respeito e terror, aquele ao qual era preciso submeter-se, porque ele reinava, era o discurso pronunciado por quem de direito e conforme o ritual requerido, era o discurso que pronunciava a justiça e atribuía a cada qual sua parte [...]. Ora, eis que um século mais tarde, a verdade a mais elevada já não residia mais no que era o discurso, ou no que ele fazia, mas residia no que ele dizia: chegou um dia em que a verdade se deslocou do ato ritualizado, eficaz e justo, de enunciação, para o próprio enunciado (FOUCAULT, 2012: 14-15). 
A "verdade" sobre Tiradentes foi construída, desconstruída, reconstruída e transformada pelos discursos dos autores aqui analisados. Consideramos, a partir do exame das obras, que ambos os autores tinham como objetivo construir o sujeito Tiradentes a partir das perspectivas de poder político ao qual estavam ligados. Sendo a Inconfidência Mineira um movimento representativo para os republicanos, e Tiradentes sua figura mais emblemática por ter sido condenado à morte, o discurso monarquista aqui representado por Joaquim Norberto de Souza e Silva buscará a construção de uma imagem negativa do alferes, como forma de conter o avanço de sua figura como símbolo republicano. Tornando-se referência, o discurso de Silva será mais tarde deslegitimado por Lúcio José dos Santos, que além de desqualificar a narrativa do monarquista busca consolidar a imagem de um Tiradentes mítico e heroico, que vinha sendo construída desde o advento do movimento republicano no Brasil. O sujeito histórico Tiradentes é fruto dessas construções e desconstruções discursivas.

Como nos confirma Albuquerque Júnior (2007: 187), as “verdades" históricas tratamse de construções, de "invenções" dadas a partir dos discursos.

As palavras nunca dão conta de revelar a verdade das coisas [...] Uma história praticada como sátira sabe, de antemão, que mais inventa seu objeto do que revela sua verdade e que a verdade deste objeto que ela inventa está nas formações discursivas e nos regimes de práticas que presidiram, em dada época, a sua invenção. A história se assume como discurso produtor de verdades e construtor de realidades, politicamente interessadas.

Albuquerque Júnior afirma ainda que "todo evento histórico é cultural e simbólico e precisa de alguma forma de linguagem para acontecer, para estabelecer os laços de comunicação entre os homens" (idem: 27). Os intelectuais aqui estudados criaram o evento Inconfidência Mineira e a personagem Tiradentes sob suas próprias óticas, através da linguagem escrita, e tendo como diretrizes as circunstâncias políticas com as quais estavam ligados. Ademais, os autores enfatizaram ou ocultaram determinadas características e atitudes do alferes, tendo como objetivo diminuir sua importância ou exaltar sua participação na Inconfidência Mineira. Os discursos dos historiadores construíram a realidade.

Sabemos que os discursos fazem parte de conjunturas específicas, representam suas épocas e os respectivos interesses em jogo. A disputa ideológica entre monarquistas e republicanos, aqui representada pelos autores analisados, influenciou diretamente a construção da figura de Tiradentes enquanto mártir heroico. O poder político vigente foi determinante para a estruturação do discurso em torno do mito, e o próprio embate discursivo já se configurou como disputa de poder. "O discurso não é simplesmente aquilo que traduz as 
lutas ou os sistemas de dominação, mas aquilo porque, pelo que se luta, o poder do qual nos queremos apoderar" (FOUCAULT, 2012: 10).

Os intelectuais em questão, como já dito, estavam ligados aos poderes políticos monárquico e republicano, e seus discursos tinham força, pois partiam de homens letrados e respeitados dentro de seus contextos. Sendo assim, suas falas foram forjadas pelas conjunturas políticas que defendiam, e também apropriadas por estas como legitimadoras da causa. Sobretudo o discurso de Santos contribuiu para a criação do herói nacionalista republicano Tiradentes, conforme já apontamos. Ao constatarmos que Tiradentes ainda hoje é um forte símbolo celebrado pelo panteão cívico brasileiro, concluímos que o discurso republicano representado aqui pelo estudo de Santos obteve êxito em seu objetivo, sendo assimilado pela sociedade, que celebra Tiradentes ainda hoje através de rituais e práticas (celebrações em escolas; desfiles; o feriado nacional no dia de sua execução, 21 de abril).

Assim, para a nação brasileira e para a República recém-criada, Tiradentes era um herói que personificava os interesses políticos, mas também os anseios populares. Caso contrário, não teria sido bem aceito e festejado pela população, algo que inclusive perdura até os dias de hoje. O imaginário popular é permeado por símbolos e mitos, e o heroísmo de Tiradentes foi legitimado pelo discurso do poder institucional, mas ao mesmo tempo pela aceitação popular, principalmente devido ao apelo religioso da comparação com Jesus Cristo. O herói, sob esta perspectiva, é uma fabricação, o resultado de uma prática discursiva criada pelos que estão no poder, mas somente estabelecida porque aceita pelo público.

Concluímos afinal que as obras de Joaquim Norberto de Souza Silva e Lúcio José dos Santos são emblemáticas, visto que através de suas narrativas podemos compreender a importância do discurso histórico como base para a legitimação dos interesses políticos e poderes vigentes. Os autores eram homens de seu tempo, apreenderam o pensamento do meio em que estavam inseridos e refletiram essas ideias em suas obras, construindo assim importantes interpretações históricas que ainda hoje são alvo de estudo e debates entre os estudiosos da Inconfidência Mineira e de seu mais polêmico participante, o alferes Tiradentes.

\section{Referências bibliográficas}

ALBUQUERQUE JÚNIOR, Durval Muniz de. História: A arte de inventar o passado. Ensaios de teoria da história. São Paulo: Edusc, 2007.

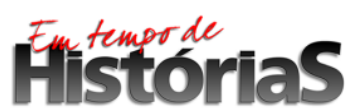


CARVAlHO, José Murilo de. A formação das almas: o imaginário da República no Brasil. São Paulo: Companhia das Letras, 1990.

FOUCAULT, Michel. A Ordem do Discurso. Aula inaugural no College de France, pronunciada em 2 de dezembro de 1970. São Paulo: Ed. Loyola, 2012.

GUIMARÃES, Manoel Luís Salgado. "Nação e civilização nos trópicos: o Instituto Histórico e Geográfico Brasileiro e o Projeto de uma História Nacional". Revista Estudos Históricos. Rio de Janeiro: Fundação Getúlio Vargas, 1988.

MICELI, Paulo. O mito do herói nacional. São Paulo: Contexto, 1994.

OLIVEIRA, José Lourenço de. $O$ educador Lúcio dos Santos. Disponível em: 〈http://www.letras.ufmg.br/lourenco/banco/EH09.html>. Acesso em: 26 jun. 2014.

SANTOS, Lúcio José dos. A Inconfidência Mineira: papel de Tiradentes na Inconfidência Mineira. São Paulo: Lyceu Coração de Jesus, 1927.

SANTOS, Lúcio José dos. A Inconfidência Mineira: papel de Tiradentes na Inconfidência Mineira. Belo Horizonte: Imprensa Oficial, 1972.

SILVA, Joaquim Norberto de Souza. História da Conjuração Mineira. Rio de Janeiro: Imprensa Nacional, 1948. Disponível em <http://www.literaturabrasileira.ufsc.br/documentos/?action=download\&id=28196> Acesso em: 19 jun. 2014.

SOARES, Sônia Regina Pinto. Joaquim Norberto de Souza Silva: historiador. Um olhar sobre Minas Gerais colonial. Disponível em: 〈http://www.bibliotecadigital.unicamp.br/document/?code=000224722 > Acesso em: 19 jun. 2014.

SOUZA, Roberto Acízelo de. Joaquim Norberto e sua contribuição à edição de textos e à crítica literária. Disponível em: 〈http://seer.fclar.unesp.br/letras/article/view/930>. Acesso em 19 jun 